\title{
Intraplate depth-dependent lithospheric stretching imaged by seismic reflection data
}

\section{Shuwen Dong ( $\nabla$ swdong8888@126.com )}

Nanjing University

\section{Jianhua Li}

Institute of Geomechanics, Chinese Academy of Geological Sciences

\section{Rui Gao}

Institute of Geology, Chinese Academy of Geological Sciences

\section{Peter Cawood}

Monash University https://orcid.org/0000-0003-1200-3826

\section{Hans Thybo}

Istanbul Technical University https://orcid.org/0000-0002-3945-8065

\section{Yueqiao Zhang}

Institute of Geomechanics, Chinese Academy of Geological Sciences

\section{Stephen Johnston}

University of Alberta https://orcid.org/0000-0002-7384-0890

\section{Jinming Wang}

Institute of Geomechanics, Chinese Academy of Geological Sciences

\section{Article}

Keywords: seismic reflection profile, kinematic decoupling, mechanically stratified lithosphere

Posted Date: August 18th, 2021

DOl: https://doi.org/10.21203/rs.3.rs-733095/v1

License: (c) (i) This work is licensed under a Creative Commons Attribution 4.0 International License. Read Full License 
2 Intraplate depth-dependent lithospheric stretching imaged by seismic reflection data

4

5 Shuwen Dong ${ }^{1,2, *}$, Jianhua $\mathrm{Li}^{3 *}$, Rui Gao ${ }^{4}$, Peter A. Cawood ${ }^{5}$, Hans Thybo ${ }^{6}$, Yueqiao Zhang $^{1}$, Stephen T. Johnston ${ }^{7}$, Jinming Wang ${ }^{3}$

7

81 State Key Laboratory for Mineral Deposits Research, Nanjing University, Nanjing 9 210023, China

102 SinoProbe Center, Chinese Academy of Geological Sciences, Beijing 100037, China

$11{ }^{3}$ Key Laboratory of Paleomagnetism and Tectonic Reconstruction, Ministry of Natural

12 Resources, Institute of Geomechanics, Chinese Academy of Geological Sciences, Beijing

13 100081, China

$14{ }^{4}$ School of Earth Science and Geological Engineering, Sun Yat-sen University, Guangzhou, 15 510275, China

$16{ }^{5}$ School of Earth, Atmosphere \& Environment, Monash University, Melbourne, VIC 3800 ,

17 Australia

$18{ }^{6}$ Eurasia Institute of Earth Sciences, Istanbul Technical University, Istanbul, Turkey

$19{ }^{7}$ Earth and Atmospheric Sciences, University of Alberta, Edmonton, Alberta, Canada 20

$21 *$ Corresponding authors:

22 Shuwen Dong (email: swdong@nju.edu.cn; swdong8888@ 126.com)

23 Jianhua Li (email: lijianhua0301@126.com) 


\section{Abstract}

26 Geological and geophysical data coupled with numerical simulations have shown that

27 lithospheric extension at passive margins may be classified into three end-member 28 scenarios of pure shear, simple shear, and depth-dependent deformation. However, how 29 lithospheric extension evolves in an intraplate setting remains enigmatic due to lack of 30 reliable constraints on the deep lithospheric architecture. Here we use a seismic reflection 31 profile across the $\sim 800-\mathrm{km}$-wide Cretaceous intraplate extensional system of South China 32 to illustrate depth-dependent kinematic decoupling of extension in a mechanically stratified 33 lithosphere. The extension was initially distributed in magma-poor conditions as expressed 34 by normal faulting in the upper crust and lower-crustal flow toward the rift axis. Necking 35 of the crust and Moho uplift led to mantle shear-zone formation, lower-crustal flow toward 36 the rift flanks, and deep mantle flow. We demonstrate that the extensional modes vary with 37 decreasing mantle strength from magma-poor to magma-rich domains, as reflected in 38 decreasing crust-mantle decoupling with increased Moho temperatures $\left(\mathrm{T}_{\mathrm{M}}\right)$, and the 39 replacement of a two-layer (brittle vs ductile) mantle by a fully ductile mantle. These 40 findings reveal a first-order lithospheric configuration of intraplate depth-dependent 41 extension driven by far-field stresses attributable to slab retreat. 
Extensional overprinting or disruption of contractional tectonics is a common feature

43 of continental lithospheric evolution of the Earth ${ }^{1}$. Lithospheric extension involves a

44 variety of geological processes including crustal thinning, magmatism, exhumation, Moho

45 uplift, and mantle convection ${ }^{2-4}$, results in vigorous crust-mantle interaction, and promotes

46 hydrothermal circulation. All these processes are vital for shaping the Earth's lithospheric

47 architecture ${ }^{5-7}$. Despite decades of research on rifted passive margins ${ }^{8-10}$, considerable

48 controversy exists regarding the nature of lithospheric extension, reflected in three

49 competing tectonic models. The pure-shear stretching model, as inferred from

50 mathematical modeling, predicts in situ, coaxial, and horizontal stretching of the crust, with

51 coupled vertical thinning in the mantle lithosphere ${ }^{11}$ (Fig. S1). A modification to this model

52 envisages decoupling of a heterogeneously deforming brittle upper crust from a ductile

53 middle/lower crust with more evenly distributed deformation, leading to two-layer crustal

54 stretching ${ }^{12}$. The simple-shear stretching model, linking crustal displacements over discrete

55 areas via a low-angle $\left(<30^{\circ}\right)$, lithosphere-penetrating fault zone, assumes that extension is

56 largely accommodated by non-coaxial faulting along a lithospheric-scale detachment ${ }^{1,13}$

57 (Fig. S1). The depth-dependent stretching model, which focuses on extensional mechanics

58 and rheological behavior, predicts that lithospheric stretching varies with depth and

59 involves mechanical decoupling and ductile flow between strong layers ${ }^{9,14,15}$. Although

60 these models predict distinct crustal and mantle structures, differentiation among them has

61 been hampered by the lack of high-resolution seismic reflection data. In contrast to

62 abundant studies of hyperextension and extreme crustal thinning in passive margins, little

63 attention has been paid to continental interiors or intraplate regions, where relatively mild

64 extension is induced by far-field effects including slab retreat or rollback. Two key issues 
65 remain elusive regarding (1) how the intraplate extensional strain is vertically partitioned

66 within the lithospheric column, and (2) how the extensional modes vary laterally across a

67 broad intraplate system. Addressing these issues has implications for understanding

68 intraplate extension located hundreds of kilometers away from the convergent margin, and

69 for placing enigmatic intraplate extensional processes within the plate tectonic paradigm ${ }^{16}$.

70 Here we address these issues through SINOPROBE seismic reflection profiling of the

71 Cretaceous extensional system of South China (Fig. 1). This system, extending over 800

$72 \mathrm{~km}$ inboard of the convergent margin, is as spectacular as the Basin and Range Province in

73 North America ${ }^{17}$. It underwent two stages ( 140-120 Ma and $\left.\sim 110-80 \mathrm{Ma}\right)$ of extension

74 (Fig. S2) that gave rise to rift basins $\left(\sim 123,000 \mathrm{~km}^{2}\right)^{18}$, metamorphic core complexes ${ }^{19}$, and

75 voluminous magmatic bodies restricted to eastern South China $\left(\sim 140,000 \mathrm{~km}^{2}\right)^{18}$ (Fig. 1).

76 Our new seismic observations, beyond the igneous province, suggest a stratified and

77 mechanically decoupled lithosphere that underwent differential stretching via depth-

78 dependent extension in magma-poor conditions. Combined with published seismic

79 reflection data, we elucidate lateral variations in modes of extension across different

80 domains within the broad extensional system, and present a first-order configuration

81 showing how intraplate depth-dependent lithospheric extension is expressed.

\section{New seismic reflection data across the extensional system}

84 Seismic processing includes automatic gain control, refraction statics, and migration,

85 cf. Methods. Stacked and migrated profiles were used to define reflections (Fig. S3);

86 detailed surface geology is given in Fig. S4. Line drawings were made from the migrated

87 profile without vertical exaggeration (Fig. 2a), to show tectonic events of differing 
coherency. Detailed descriptions of the seismic reflections are provided in Appendix 1.

Here we focus on the first-order features to clarify the overall structural framework.

The upper and middle crust is characterized by abundant reflections that display lateral variations in geometry and amplitude (Fig. 2a), implying heterogeneous strain and changes in structural style along the profile. In the northwestern part, CDPs (Common Depth Points) 22500-24500, contains three NW-dipping reflections ( $F_{1}, F_{2}$ and $F_{3}$, Fig. 2a) that truncate two arcuate packages of laminar reflections (A and B) and which merge into a $\sim 0.5$ s-thick, subhorizontal, high-reflective zone $\left(D_{1}\right)$; this pattern corresponds to three NW-dipping thrusts truncating hanging-wall folds and merging into a subhorizontal decollement $\left(D_{1}\right)$, indicative of southeastward thrust imbrication (Figs. 3a and S4). Below event $\mathrm{D}_{1}$, a thin zone of gently, SE-dipping reflections ( $\mathrm{D}_{2}$, at CDPs 24000-27000) steepens upwards, truncates underlying reflections and approaches $\mathrm{D}_{1}$. Together, $\mathrm{D}_{1}$ and $\mathrm{D}_{2}$ form a critical-taper wedge accommodating contractional strain transfer between the upper and middle crust (Fig. 3). Comparable contraction-related features prevail in the southeastern part of the section. Therein three mid-crustal reflections $\left(\mathrm{D}_{3}, \mathrm{D}_{4}\right.$ and $\left.\mathrm{D}_{5}\right)$ exhibit flat-rampflat stair-step trajectories (Fig. 2a). Sudden changes in reflection dip occur across the ramps, where underlying (footwall) subhorizontal reflections are truncated by the ramps, whereas overlying reflections are parallel to the ramps (hanging-wall flats) (Fig. 2a). Folding of hanging-wall reflectors forms thrust-ramp folds. The overall pattern of these reflections resembles a thin-skinned thrust-and-fold system with multiple decollements (Fig. 3).

These contractional systems are truncated by normal faults, which are seismically manifested as diffractive zones that (1) bound hanging-wall, wedge-shaped reflections corresponding to Cretaceous growth strata within half grabens ( $\mathrm{F}_{10}$ and $\mathrm{F}_{11}, \mathbf{F i g}$. 2a); or (2) 
111 displace laterally coherent reflections with normal-sense offsets ( $F_{12}$ and $\left.F_{13}\right)$. The central 112 part of the section (CDPs 26500-29500) is characterized by extension-related reflections 113 defining the Hengyang Basin, manifested by laminar, gentle-dipping reflections that are 114 truncated by a series of conjugate normal faults (Fig. 2b), corresponding to Cretaceous 115 strata deformed by distributed normal faulting (Fig. 3). The basin is underlain by a domain 116 almost devoid of reflections that truncates mid-crustal contractional systems to the NW 117 and SE (Fig. 2a), suggesting that the thermal-mechanical extensional tectonism has almost 118 completely overprinted the compressional structures below the Hengyang Basin.

119 The lower crust is attenuated and highly reflective (Fig. 2a). Although the reflectivity 120 changes character slightly in amplitude and coherence, it is characterized by finely121 laminated, subhorizontal reflections with a thickness (measured in two-way time) of 4-5s 122 extending across the entire section (Lc in Figs. 2c, d). Bands of gently dipping (20-30 $)$ 123 sets of SE-dipping reflections $\left(\mathrm{S}_{1}\right.$ and $\left.\mathrm{S}_{2}\right)$ occur between the subhorizontal reflection bands, 124 giving the impression of parallel arrays of high-strain structures (Figs. 2c, d).

125 The Moho (M) is imaged as the transition between the highly reflective lower crust 126 and the largely transparent upper mantle. The Moho shows long-wavelength deformation, 127 rising to $11 \mathrm{~s}$ below the Hengyang Basin from depths of 12-12.5 s (Fig. 2a) in the 128 surrounding region, indicating a variation of crustal thickness in the order of 1-1.5 s (3-4.5 $129 \mathrm{~km})$.

130 Below the Moho, the most striking feature is a conjugate set of three gently dipping $131\left(20-30^{\circ}\right)$, highly reflective zones that extend down from Moho to $\sim 13 \mathrm{~s}$ depth within an 132 otherwise seismically transparent mantle (Fig. 2e). These reflection zones dip away from 133 the centre of the Moho uplift on both sides. 


\section{Intraplate depth-dependent stretching of stratified lithosphere}

135 Our analysis of seismic reflection data leads to the following first-order observations

136 (Figs. 3 and S5). First, the upper and middle crustal reflections suggest an overall structural

137 architecture of crustal shortening extensively modified by normal faults due to subsequent

138 extension. Second, the lower crust shows pervasive, finely-laminated, subhorizontal

139 reflections around groups of inclined reflections $\left(S_{1}\right.$ and $\left.S_{2}\right)$. Third, the Moho is smooth

140 and continuous, and shows an upward arching spatially associated with upper-crustal

141 normal faults, reflecting the locus of crustal necking; the thinnest crust is immediately

142 beneath the Hengyang basin. Fourth, conjugate high-amplitude reflections dip away from

143 the centre of the Moho uplift in an otherwise transparent upper mantle.

144 We interpret the lower-crustal reflections to represent a combination of two end145 member hypotheses, i.e., strain-related banding due to extensive ductile flow within a 146 rheologically weak lower crust ${ }^{20,21}$, and localized mafic sills or intrusions ${ }^{22,23}$. Wide-angle 147 seismic data of the lower crust indicate a P-wave velocity of $6.5-6.8 \mathrm{~km} / \mathrm{s}$ lower than that $148(>7.0 \mathrm{~km} / \mathrm{s})$ of mafic-ultramafic lower crust ${ }^{24}$, confirming an overall more felsic and hence 149 weaker lower crust. Therein the finely laminated reflections likely reflect a pervasive 150 mylonitic foliation formed by simple-shear deformation during channelized flow ${ }^{20,25}$. The

151 presence of localized mafic sills are consistent with two lines of evidence: (1) the lower 152 crust shows localized zones of high reflectivity concentrated in distinct bands $\left(\mathrm{H}_{1}-\mathrm{H}_{3}\right.$, Fig. 153 2a); and (2) surface exposures of mafic dikes and basalts show high $\varepsilon_{\mathrm{Nd}}(\mathrm{t})$ values (-2.2 to 154 7.2) and low La/ $\mathrm{Nb}$ ratios $(0.59 \text { to } 1.59)^{26}$. Such evidence demonstrates localized mantle 155 underplating and influx in the form of layered mafic sills within a more felsic lower crust.

156 Gentle to moderate $S_{1}$ and $S_{2}$ foliations may represent imbricated, anastomosing shear 
157 zones that alternate with low-strain domains, i.e., highly deformed and sheared zones

158 surrounding undeformed, transparent $\operatorname{areas}^{25}$. They resemble S-foliations at small angles

159 to the subhorizontal shear bands (i.e., C-foliations) within major shear zones (Fig. 3). This

160 spatial relationship probably represents constructive interference of small-scale seismic

161 signals which, nevertheless, preserve the overall structure originating from ductile shearing

162 and plastic deformation during lower-crustal flow. The recognition of channelized flow

163 supports the interpretation that the weakest layer of the continental lithosphere resides in

164 the lower crust, not, as is commonly assumed, in the middle crust ${ }^{27}$. One further issue

165 concerns the direction of flow. By incorporating results from numerical simulations ${ }^{10,15}$,

166 we suggest two stages of flow due to buoyancy-driven forces caused by crustal and mantle

167 lithosphere thinning, respectively. The initial flow was inward toward the rift axis (1) in

168 Fig. 3), driven by a lateral pressure gradient created by localized thinning of the upper 169 crust $^{28}$, a mechanism akin to that responsible for the formation of metamorphic core 170 complexes $^{29}$. As extension and thinning continue, increased mantle-dominated buoyancy

171 forces, including mantle lithosphere thinning, Moho uplift and asthenospheric upwelling ${ }^{10}$, 172 reversed the flow direction and drove the lower crust to flow outwards toward the rift flanks 173 (2) in Fig. 3). The channelized flow mechanically decoupled upper-middle crustal 174 deformation from mantle deformation. The decoupling pattern, manifested by individual 175 stretching of upper crust and upper mantle about the same rift axis (Fig. S5), indicates 176 diffuse decoupling ${ }^{30}$. Studies on governing equations demonstrate that such decoupling 177 occurs when the ratio of $u_{p} \cdot h_{0} / k_{c f}<100\left(k_{c f}\right.$, the diffusion constant; $u_{p}$, the plate spreading 178 velocity; $h_{0}$, the crustal thickness $)^{30}$. We calculate the initial Moho temperature $\left(T_{M}\right)$ of the 179 study area by plotting $\log \left(u_{p} \cdot h_{0} / k_{c f}\right)$ vs $T_{M}$ using the equations from refs. 30, 31 (Table S1). 
180 Results suggest that, for both wet and dry $40 \mathrm{~km}$ thick quartz crust, the diffuse decoupling 181 herein occurred at $\mathrm{T}_{\mathrm{M}} \sim 440-640{ }^{\circ} \mathrm{C}$ (Fig. S6), comparable to that of non-volcanic passive 182 margins $^{32}$.

183 We interpret the mantle reflectors as ductile shear zones that reflect strain localization 184 in the uppermost mantle (Fig. 3), because (1) mantle strain localization involves grain size 185 reduction in olivine ${ }^{33}$ that can decrease viscosity and cause attenuation of seismic shear 186 waves $^{34}$; and (2) the layering of mantle mylonites can cause differential acoustic 187 impedances and hence high reflectivity ${ }^{35}$. Similar mantle shear zones have been reported 188 beneath other continental rifts (e.g., the North Sea Basin in Europe) ${ }^{36,37}$. They generally 189 initiate in the crustal necking stage when strain in the crust and mantle begins to link ${ }^{14}$, and 190 accommodate large-scale displacement away from the mantle dome ${ }^{14,27}$. We infer that 191 these shear zones control the exhumation and ascent of the deeper mantle; such shear zones 192 were reproduced in analogue models of mantle exhumation at passive margins ${ }^{29}$.

193 The imaged lower-crustal flow and mantle shear-zone formation are interpreted as 194 concomitant Cretaceous extensional features, because: (1) they show well-defined spatial 195 association and kinematic consistency with upper-crustal Cretaceous normal faults and the 196 Moho uplift, respectively; and (2) seismic profiling primarily images structures attributable 197 to the most recent and intensive tectonic event affecting the crust ${ }^{38}$, herein corresponding 198 to the remarkable Cretaceous extensional event. Despite the synchronism of crustal and 199 mantle extension, discrepancies exist regarding the amounts and modes of extension both 200 within the crust and between the crust and mantle. Specifically, although the upper and 201 lower crust underwent extension across a wide region, upper crustal extension was 202 characterized by localized thinning via normal faulting, whereas the lower crust was 
203 stretched by channelized flow but in a more distributed fashion across the entire section

204 (Fig. 3). That said, the magnitude of stretching ( $\beta \mathrm{x}=$ extended length of crust/original

205 length of crust $)^{39}$ and attenuation $(\delta x=1-1 / \beta x)^{6}$ are broadly comparable; $1.0-1.40$ and 0.0

$206-0.29$ for the upper crust versus $1.0-1.22$ and $0.0-0.18$, for the lower crust, respectively

207 (Fig. 3). In contrast to wide-scale distributed extension through the crustal profile, the

208 localized mantle shear zones focused the upper-mantle thinning in a much narrower zone

209 (Fig. 3). Such extension discrepancies suggest depth-dependent differential stretching of

210 the upper lithosphere.

211 To explore the effect of extension on the lower lithosphere, we determine deformation

212 patterns of the mantle lithosphere from seismic anisotropy ${ }^{40}$, based on a compilation of

213 shear-wave splitting measurements in South China ${ }^{41}$. The directions of mantle seismic

214 anisotropy suggest dominant NW-SE-orientated flow of the mantle lithosphere (Fig. 4a).

215 Although the fabrics beneath western South China reflect Cenozoic mantle flow 216 accommodating recent eastward expansion of the Tibetan Plateau ${ }^{42}$, eastern South China

217 has been subject to negligible Cenozoic deformation ${ }^{43}$ and hence mantle fabrics are mostly

218 'fossil' signals that are relics of Cretaceous flow. The NW-SE flow direction is parallel to 219 the stretching lineation of metamorphic core complexes (Fig. 4b) consistent with dominant 220 lower-crustal flow during extension ${ }^{44}$. The remarkable parallelism demonstrates that the 221 lower crust and mantle lithosphere flowed in the same direction during lithospheric 222 stretching (Fig. 4a). The flow direction is consistent with regional NW-SE-oriented 223 extensional stresses (Fig.4a, b) that dominated the opening of upper-crustal basins ${ }^{19}$.

224 The above observations differ from the predictions of the simple-shear and pure-shear 225 hypotheses. First, the differential stretching of the lithosphere, coupled with depth- 
226 dependent stretching and attenuation factors, is inconsistent with the uniform extension

227 predicted by the simple-shear model ${ }^{11}$. Second, the absence of a lithosphere-penetrating 228 reflection zone is incompatible with the simple-shear model ${ }^{1,13}$ on predicting 229 accommodation of lithospheric extension along a single low-angle detachment. Instead, 230 our observations support a four-layer stratified lithosphere that was stretched by depth231 dependent extension in magma-poor conditions (Fig. 5a). The extension appears to 232 comprise two successive stages with respect to initiation and amplification. First, 233 distributed thinning of the upper crust by normal faulting (A, Fig. 5a) was matched by 234 lower-crustal flow toward the rift axis to compensate for upper-crustal thinning (B) and 235 possible slight exhumation of upper mantle (C). This initial stage was followed by crustal 236 necking capable of generating an arched Moho (D), localized mantle exhumation prompted 237 by mantle shear-zone formation (E), lower-crustal flow toward the rift flanks (F) and 238 mantle influx into the crust in the form of mafic sills $(\mathrm{G})$, and mantle flow $(\mathrm{H})$ possibly 239 accompanied by small-scale mantle necking and upwelling/convection (I) as illustrated by 240 the geochemistry of coeval basalt ${ }^{26}$ and by laboratory experiments ${ }^{45}$.

\section{Lateral variation in modes of depth-dependent extension}

242 To elucidate lateral variation in modes of depth-dependent extension, we reconstruct 243 the overall architecture of the broad ( 800-km-wide) intraplate extension driven by slab 244 retreat (Fig. 5b), by integrating the complete $>1000-\mathrm{km}$-long seismic reflection data across 245 South China ${ }^{43,46}$ (Fig. 1). Based on the distribution of compressional/extensional structures 246 and magmatic activity, we define three domains, a western pre-rift domain, a central 247 magma-poor domain, and an eastern magma-rich domain (Fig. 5b). The pre-rift domain 248 shows a thick, stratified crust that lacks any Cretaceous thermal perturbations ${ }^{46}$ (Fig. 5b). 
249 The presence of a high-viscosity lower crust requires vertically coherent deformation (e.g., 250 the thin-viscous-sheet model $^{47}$ ), and precludes large rheological contrasts and lower-crustal 251 flow within the lithosphere, implying crust-mantle coupling at low $\mathrm{T}_{\mathrm{M}}<480{ }^{\circ} \mathrm{C}^{32}$. In 252 contrast to the central magma-poor domain (Fig. 5a), the eastern magma-rich domain ${ }^{43}$ 253 shows different extensional characteristics, including (Fig. 5b): upper-crustal normal 254 faulting and dilation by magmatic injection (A); lower-crustal flow and melting (B); 255 basaltic underplating (C); mantle influx into the lower crust in the form of layered mafic 256 sills (D); Moho shallowing by 2-4 km (E); partial melting in the mantle lithosphere (F); 257 and asthenospheric upwelling (G). Extensive lower-crustal partial melting implies a high $258 \mathrm{~T}_{\mathrm{M}}>700{ }^{\circ} \mathrm{C}^{32}$; this was reflected in decreased crustal-mantle decoupling, due to the 259 absence of a high-strength mantle at high temperatures ${ }^{32}$. From pre-rift to magma-poor 260 domains, regional extension caused a transition from a coupled to a decoupled style of 261 lithospheric deformation associated with increasing $\mathrm{T}_{\mathrm{M}}$, due to rheological weakening of 262 the lower crust (Fig. 5b). From magma-poor to magma-rich domains, the extension seems 263 to be facilitated by magmatism, and involves the following variations: (1) the replacement 264 of a two-layer (brittle vs ductile) mantle lithosphere by a wholly ductile mantle lithosphere; 265 (2) marked decreases in the mantle strength and crust-mantle decoupling; (3) an increase 266 in the $\mathrm{T}_{\mathrm{M}}$; and, (4) the abandonment of mantle shear zones due to intense mantle melting 267 and basaltic underplating (Fig. 5b). These lateral variations may originate from thermal 268 perturbation of the mantle by deeper asthenospheric upwelling. Our observations reveal 269 how intraplate lithospheric extension can be characterized in a general depth-dependent 270 architecture as a first-order configuration. This configuration provides a basis for 271 discussing modes of lithospheric extension in intraplate or other complex tectonic settings, 
272 such as wide versus narrow rifting ${ }^{5,29,32}$, extreme tectonic decoupling, and large-scale

273 lateral offset between upper-crustal and mantle-lithospheric extensions in the Basin and 274 Range province, $\mathrm{USA}^{48}$.

275

276 Methods

277 DATA ACQUISITION

278 The seismic data were acquired by using Sercel SN408XL 24-bit digital seismic 279 recorders with 1600 channels. Dynamite sources of $40 \mathrm{~kg}$ nominal for normal shots and $280200 \mathrm{~kg}$ nominal for large shots were fired with a spacing of $160 \mathrm{~m}$ and $5000 \mathrm{~m}$, respectively.

281 Shot spacing was reduced to $80 \mathrm{~m}$ across the mountainous regions. Dynamite for $40-\mathrm{kg}$ 282 sources was placed in single holes at depth of 22-24 m. Dynamite for 200-kg sources were 283 detonated in 25-m deep 5-hole arrays. SM-24 geophones were used with a dominant 284 frequency of $10-\mathrm{Hz}$ in a group space of $40 \mathrm{~m}$. Seismic data were recorded for $30 \mathrm{~s}$ at a 285 sampling rate of $2 \mathrm{~ms}$. The acquisition parameters are listed in Table $\mathrm{S} 2$ below.

286 Table S2 Acquisition parameters for improved standard oil-industry

287 Shot interval $160 \mathrm{~m}$ nominal for Normal shot (Basin)

$288 \quad 80 \mathrm{~m}$ nominal for Normal shot (orogen)

$2895000 \mathrm{~m}$ nominal for Large shot

290 Source Dynamite

291 Charge size $40 \mathrm{~kg}$ nominal for Normal shot

$292200 \mathrm{~kg}$ nominal for Large shot

293 Shot depth $22 \mathrm{~m} \times 2$ for Normal shot $(40 \mathrm{~kg})$

294 $25 \mathrm{~m} \times 5$ for Large shot $(200 \mathrm{~kg})$ 
295 Nominal fold 60 (Basin)

296120 (Orogen)

297 Geophone type SM24-10Hz

$298 \quad$ Number of groups 480

299 Group interval $40 \mathrm{~m}$

300 Geophone array 12 geophones in $11 \mathrm{~m}$ linear array

$301 \quad$ Near offset 20m (Normal shot)

302 140m (Large shot)

$303 \quad$ Far offset $\quad 9580 \mathrm{~m}$ (Normal shot)

304 19300m (Large shot)

305 Spread symmetric split (Normal shot)

$306 \quad$ End-on (Large shot)

307 Sample rate $2 \mathrm{~ms}$

$308 \quad$ Record length $30 \mathrm{~s}$

309 Low-cut filter $15 \mathrm{~Hz}$

310 High-cut filter $250 \mathrm{~Hz}$

311 Notch filters out

312 Layout type: 9580-20-40-20-9580 (Normal shot)

313 0-0-40-140-19300 (Large shot)

314

315 DATA PROCESSING

316 (1) Routine Processing

317 By combining the advantages of Grisys, Omega and CGG systems, we conducted seismic

318 processing following a standard procedure generally practiced in the petroleum industries. 
319 These include the key steps using the following software packages: Demultiplex, Geometry

320 Definition, Record \& Trace Edition, Stacking Area Element Parameters Chosen (for

321 crooked lines), Editing/Muting, Gain Recovery, Elevation Static, Spectral Analysis,

322 Bandpass Filtering, Velocity Analysis, Normal Moveout Correction (NMO), Residual

323 Static Correction, and Stacking and Migration.

324 Muting was accomplished by applying a fixed amplitude recovery (spherical divergence 325 and balance) designed to keep the trace amplitudes roughly constant with time and across 326 the shot records. In this way, any traces contaminated by environmental noise (wind, cattle, 327 traffic) stood out and are expressed as high-amplitude traces at depth. This is because the 328 recorded amplitude of the noise is more or less constant with time (whereas the amplitudes 329 of the seismic reflections decrease rapidly with time) and the spherical divergence 330 correction (designed to even out the seismic signal) greatly amplifies the noise. Once this 331 was done, it became straightforward to mute the noise signals from the shot records using 332 an interactive display.

333 A replacement velocity of $4000 \mathrm{~m} / \mathrm{s}$ and a reference elevation of $1200 \mathrm{~m}$ have been used 334 to calculate the elevation and static corrections. First breaks were picked manually. 335 Effective reflectivity has a bandwidth of 5 to $45 \mathrm{~Hz}$ and dominant frequency of $22 \mathrm{~Hz}$. A 336 wider pass-band was used for the pre-stack data. For the top $2.5 \mathrm{~s}$ TWT the filter 337 specifications were $(8-12-65-70 \mathrm{~Hz})$.

338 After band-pass filtering and a CMP gather, elevation and statics were applied. For 339 uplifting signal-noise ratio, Pre-stack F-K filtering and Wiener deconvolution were tested 340 but found not to improve the data significantly, and so were not applied to the data. Velocity 341 analyses were performed, but below $6 \mathrm{~s}$ the normal moveout correction is almost senseless 
342 for the velocity variation. Surface-consistent residual statics were calculated by STACK-

343 POWER method interactively with the velocity analyses. Automatic gain control, F-K filter

344 to attenuate steeply dipping events and pre-stack time migration was performed. The

345 sections are plotted with no vertical exaggeration for a velocity of $6 \mathrm{~km} / \mathrm{s}$.

346 (2) Special Processing Procedures

347 Traditional refraction methods could provide satisfactory static correction results for near-

348 surface layered structures. However, the first arrivals of shot data may be highly distorted

349 due to severe topography and rapidly variable near-surface structures. Refraction static and

350 ray-tracing tomography methods were tested but they did not help improve the data quality.

351 Instead, we apply the TSCWR technique that solves nonlinear wave equations using a

352 finite-difference method. This method was combined with the first wave's stability and the

353 flexibility of rotary to avoid the shadow effect behind high-velocity bodies. TSCWR

354 performance is faster and better in static correction than refraction and ray-tracing 355 tomography for same shot data.

356 The common pre-stack processing of commercial software packages (e.g., CGG and 357 PROMAX) and wave-equation and line-migration techniques were attempted on the 358 seismic data acquired from the mountainous areas, but the results show low signal-to-noise 359 ratios. This problem was overcome by applying an improved algorithm of Kirchhoff Pre360 Stack Time Migration in rough Earth surface (KPSTM), which is pending for a patent in 361 China.

\section{Data availability}

363 The authors declare that all data supporting the findings of this study are available within the 364 main text, figures and Supplementary Information files. 


\section{References}

366 1. Wernicke, B. Low-angle normal faults in the Basin and Range Province: nappe tectonics in an 367 extending orogen. Nature 291, 645-648 (1981).

2. Brun, J. P. \& Wenzel, F. Crustal-scale structure of the southern Rhinegraben from ECORS-DEKORP seismic reflection data. Geology 19, 758-762 (1991).

3. KRISP Working Party. Large-scale variation in lithospheric structure along and across the Kenya rift. Nature 354, 223-227 (1991).

4. Thybo, H. \& Nielsen, C. A. Magma-compensated crustal thinning in continental rift zones. Nature 457, 873-876 (2009).

5. Buck, W. R. Modes of continental lithospheric extension. Journal of Geophysical Research 96, 20161-20178 (1991).

6. Huismans, R. S. \& Beaumont, C. Complex rifted continental margins explained by dynamical models of depth-dependent lithospheric extension. Geology 36, 163-166 (2008).

7. Burov, E. \& Gerya, T. Asymmetric three-dimensional topography over mantle plumes. Nature 513, 85-89 (2014).

8. Beach, A. A deep seismic reflection profile across the northern North Sea. Nature 323, 53-55 (1986).

9. Huismans, R. \& Beaumont, C. Depth-dependent extension, two-stage breakup and cratonic underplating at rifted margins. Nature 473, 74-78 (2011).

10. Brune, S., Heine, C., Pérez-Gussinyé, M. \& Sobolev, S. V. Rift migration explains continental margin asymmetry and crustal hyper-extension. Nat Commun 5, 4014 (2014).

11. McKenzie, D. Some remarks on the development of sedimentary basins. Earth and Planetary Science Letters 40, 25-32 (1978).

12. Gans, P. B. An open-system, two-layer crustal stretching model for the Eastern Great Basin. Tectonics 6, 1-12 (1987).

13. Wernicke, B. Low-angle normal faults and seismicity: a review. Journal of Geophysical Research Solid Earth 100, 20159-20174 (1995).

14. Weinberg, R. F., Regenauer-Lieb, K. \& Rosenbaum, G. Mantle detachment faults and the breakup 
of cold continental lithosphere. Geology 35, 1035-1038 (2007).

15. Huismans, R. S. \& Beaumont, C. Rifted continental margins: the case for depth-dependent extension. Earth \& Planetary Science Letters 407, 148-162 (2014).

16. Dyksterhuis, S. \& Müller, R. D. Cause and evolution of intraplate orogeny in Australia. Geology 36, 495-498 (2008).

17. Dickinson, W. R. The Basin and Range Province as a Composite Extensional Domain. International Geology Review 44, 1-38 (2002).

18. Zhou, X., Sun, T., Shen, W., Shu, L. \& Niu, Y. Petrogenesis of Mesozoic granitoids and volcanic rocks in South China: a response to tectonic evolution. Episodes 29, 26-33 (2006).

19. Li, J.H., Zhang, Y.Q., Dong, S.W. \& Johnston, S.T. Cretaceous tectonic evolution of South China: a preliminary synthesis. Earth-Sci. Rev. 134, 98-136 (2014).

20. Hurich, C. A., Smithson, S. B., Fountain, D. M. \& Humphreys, M. C. Seismic evidence of mylonite reflectivity and deep structure in the Kettle dome metamorphic core complex, Washington. Geology 13, 577-580 (1985).

21. Reston, T. J. Evidence for shear zones in the lower crust offshore Britain. Tectonics 7, 929-945 (1988).

22. McKenzie, D. A possible mechanism for epeirogenic uplift. Nature 307, 616-618 (1984).

23. Lyngsie, S.B., Thybo, H. \& Lang, R. Rifting and lower crustal reflectivity: A case study of the intracratonic Dniepr-Donets rift zone, Ukraine. Journal of Geophysical Research 112, 1-27 (2007).

24. Zhang, Z., Xu, T., Zhao, B. \& Badal, J. Systematic variations in seismic velocity and reflection in the crust of Cathaysia: new constraints on intraplate orogeny in the South China continent. Gondwana Research 24, 902-917 (2013).

25. Abramovitz, T., Berthelsen, A. \& Thybo, H. Proterozoic sutures and terranes in the southeastern Baltic Shield interpreted from BABEL deep seismic data. Tectonophysics 270, 259-277 (1997).

26. Meng, L. F., Li, Z. X., Chen, H. L., Li, X. H. \& Wang, X. C. Geochronological and geochemical results from Mesozoic basalts in southern South China Block support the flat-slab subduction model. Lithos 132, 127-140 (2012). 
27. Nagel, T. J. \& Buck, W. R. Symmetric alternative to asymmetric rifting models. Geology 32, 937940 (2004).

28. Block, L. \& Royden, L. H. Core complex geometries and regional scale flow in the lower crust. Tectonics 9, 557-567 (1990).

29. Brun, J. P., Sokoutis, D., Tirel, C., Gueydan, F. \& Beslier, M. O. Crustal versus mantle core complexes. Tectonophysics 746, 22-45 (2018).

30. Hopper, J. R. \& Buck, W. R. Styles of extensional decoupling. Geology 26, 699-702 (1998).

31. Hopper, J. R. \& Buck, W. R. The effect of lower crustal flow on continental extension and passive margin formation. Journal of Geophysical Research Solid Earth 101, 20175-20194 (1996).

32. Gueydan, F., Morency, C. \& Brun, J. P. Continental rifting as a function of lithosphere mantle strength. Tectonophysics 460, 83-93 (2008).

33. Kirby, S. H. Rock mechanics observations pertinent to the rheology of the continental lithosphere and the localization of strain along shear zones. Tectonophysics 119, 1-27 (1985).

34. Lavier, L. L. \& Manatschal, G. A mechanism to thin the continental lithosphere at magma-poor margins. Nature 440, 324-328 (2006).

35. Frederiksen, S. \& Braun, J. Numerical modelling of strain localisation during extension of the continental lithosphere. Earth \& Planetary Science Letters 188, 241-251 (2001).

36. Klemperer, S. L., Hauge, T. A., Hauser, E. C., Oliver, J. E. \& Potter, C. J. The Moho in the northern Basin and Range province, Nevada, along the COCORP $40^{\circ} \mathrm{n}$ seismic-reflection transect. Geological Society of America Bulletin 97, 603-618 (1986).

37. Klemperer, S. L. Crustal thinning and nature of extension in the northern North Sea from deep seismic reflection profiling. Tectonics 7, 803-821(1988).

38. Burg, J. P., Sokoutis, D. \& Bonini, M. Model-inspired interpretation of seismic structures in the Central Alps: Crustal wedging and buckling at mature stage of collision. Geology 30, 643-646 (2002).

39. Daley, E. E. \& DePaolo, D. J. Isotopic evidence for lithospheric thinning during extension: Southeastern Great Basin. Geology 20, 104-108 (1992). 
40. Brun, J. P. \& Sokoutis, D. 45 m.y. of Aegean crust and mantle flow driven by trench retreat. Geology 38, 815-818(2010).

41. Huang, Z. C., Wang, L. S., Zhao, D. P., Mi, N. \& Xu, M. J. Seismic anisotropy and mantle dynamics beneath China. Earth \& Planetary Science Letters 306, 105-117 (2011).

42. Wang, C. Y., Flesch, L. M., Silver, P. G., Chang, L. J. \& Chan, W. W. Evidence for mechanically coupled lithosphere in central Asia and resulting implications. Geology 36, 363-366 (2008).

43. Dong, S. W., Li, J. H., Cawood, P. A., Gao, R., Zhang, Y.Q. \& Xin, Y.J. Mantle influx compensates crustal thinning beneath the Cathaysia Block, South China: Evidence from SINOPROBE reflection profiling. Earth and Planetary Science Letters 544, 116360 (2020).

44. Costa, S. \& Rey, P. Lower crustal rejuvenation and growth during post-thickening collapse: insights from a crustal cross section through a Variscan metamorphic core complex. Geology 23, 905-908 (1995).

45. Mondy, L. S., Rey, P. F., Duclaux, G. \& Moresi, L. The role of asthenospheric flow during rift propagation and breakup. Geology 46, 103-106(2018).

46. Li, J. H., Dong, S. W., Cawood, P. A., Zhao, G. C., Johnston, S. T., Zhang, Y. Q. \& Xin, Y. J. An Andean-type retro-arc foreland system beneath northwest South China revealed by SINOPROBE profiling. Earth \& Planetary Science Letters 490, 170-179(2018).

47. England, P. \& Houseman, G. Finite strain calculations of continental deformation: 2. Comparison with the India-Asia Collision Zone. Journal of Geophysical Research Solid Earth 91, 3664-3676 (1986).

48. Schulte-Pelkum, V., Biasi, G., Sheehan, A. \& Jones, C. Differential motion between upper crust and lithospheric mantle in the central Basin and Range. Nature Geosci 4, 619-623 (2011).

49. Li, J. H., Cawood, P. A., Ratschbacher, L., Zhang, Y. Q., Dong, S. W., Xin, Y. J., Yang, H. \& Zhang, P.X. Building Southeast China in the late Mesozoic: insights from alternating episodes of shortening and extension along the Lianhuashan fault zone. Earth-Sci. Rev 201, 1-29 (2020).

50. Regenauer-Lieb, K., Weinberg, R. \& Rosenbaum, G. The effect of energy feedbacks on continental strength. Nature 442, 67-70 (2006). 


\section{Acknowledgements}

474 This work was financially supported by grants from Natural Science Foundation of China

475 (41822205), Sino-Probe (08-01), National Key R\&D Program of China

476 (2017YFC0601402). Peter Cawood acknowledges support from Australian Research

477 Council grant FL160100168.

\section{Author contributions}

479 S.D. and J.L. conceived this study. R.G. and S.D. managed the project and supervised

480 data acquisition. J.L., S.D., P.A.C., H.T. and S.T.J. did the data analysis and wrote the 481 manuscript. All of the authors contributed to the data interpretation.

\section{Competing interests}

483 The authors declare no competing financial interests.

484 Additional information

485 Supplementary information is available in the online version of the paper. 


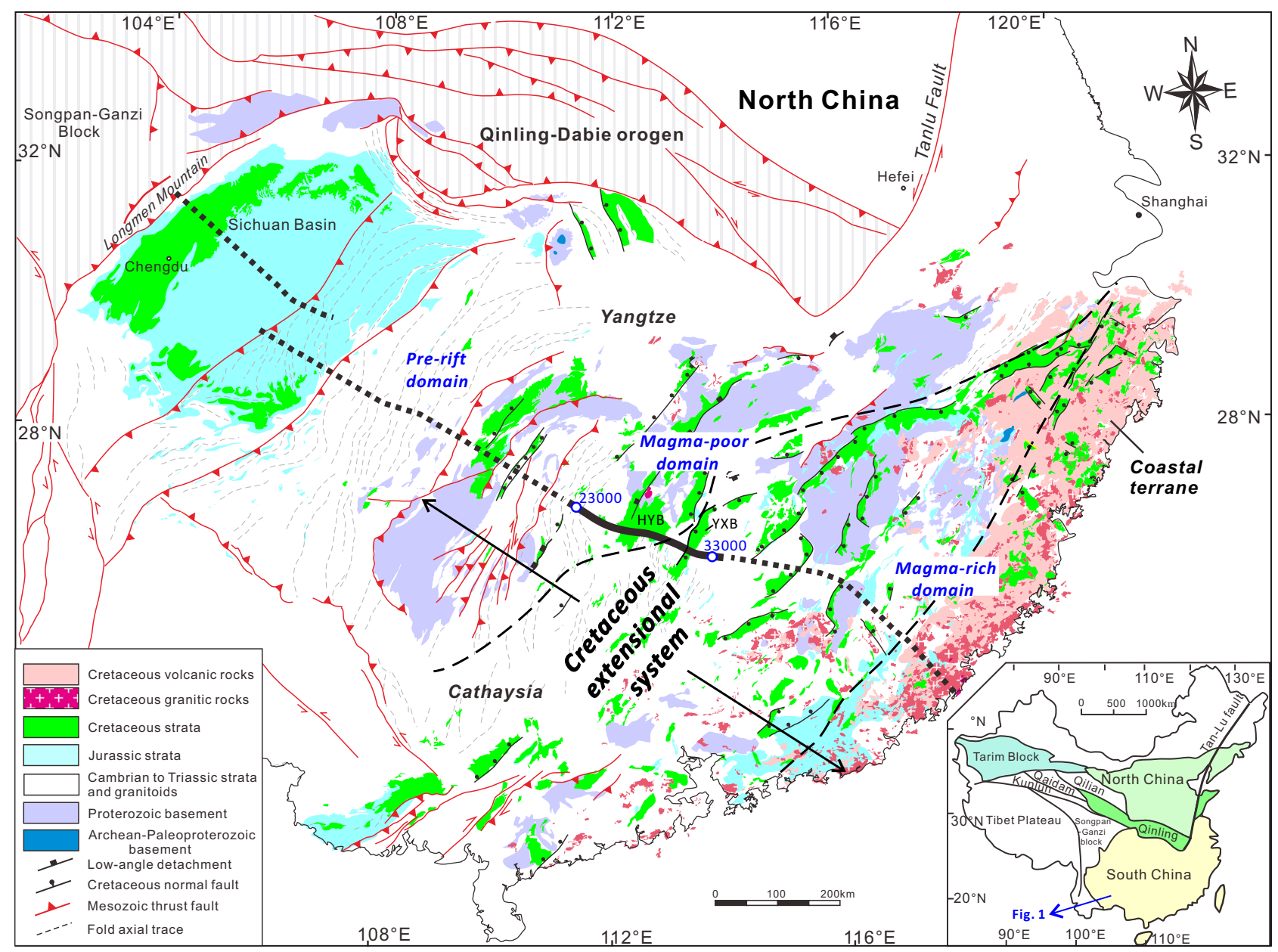

Fig. 1 Geological sketch map of South China. Simplified geologic map showing the extent of the Cretaceous extensional system in South China. The black solid line indicates the seismic line combined to form the cross section in Fig. 2a; the dotted lines indicate other seismic profiles ${ }^{43,46}$ finished by SINOPROBE. Abbreviations: HYB, Hengyang basin; YXB, Yongxing basin. Inset shows the location of South China in the tectonic framework of the People's Republic of China. 


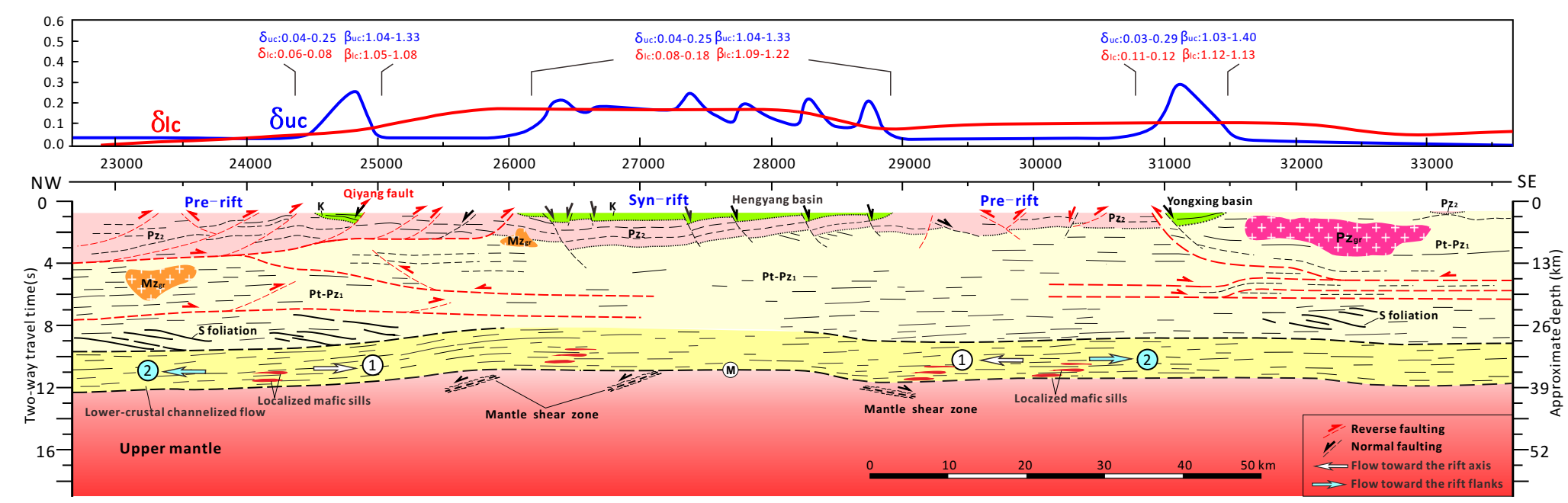

Fig. 3 Interpreted profile and calculated crustal attenuation factors. The lower sub-figure shows interpreted profile. To ensure the plausibility and testability, our interpretations are consistent with surface geology, regional tectonic evolution, existing geophysical constraints, and principles of mass conservation and balance. The upper subfigure shows plots of upper and lower crustal attenuation factors $\left(\delta_{\mathrm{uc}}\right.$ and $\left.\delta_{\mathrm{lc}}\right)$ of the profile. The crustal attenuation factor is defined as $\delta_{x}=1-1 / \beta_{x}$, where $\beta_{x}$, the crustal thinning/stretching factor, is defined as $\beta_{x}=$ extended length of crust/original length of crust. 
a

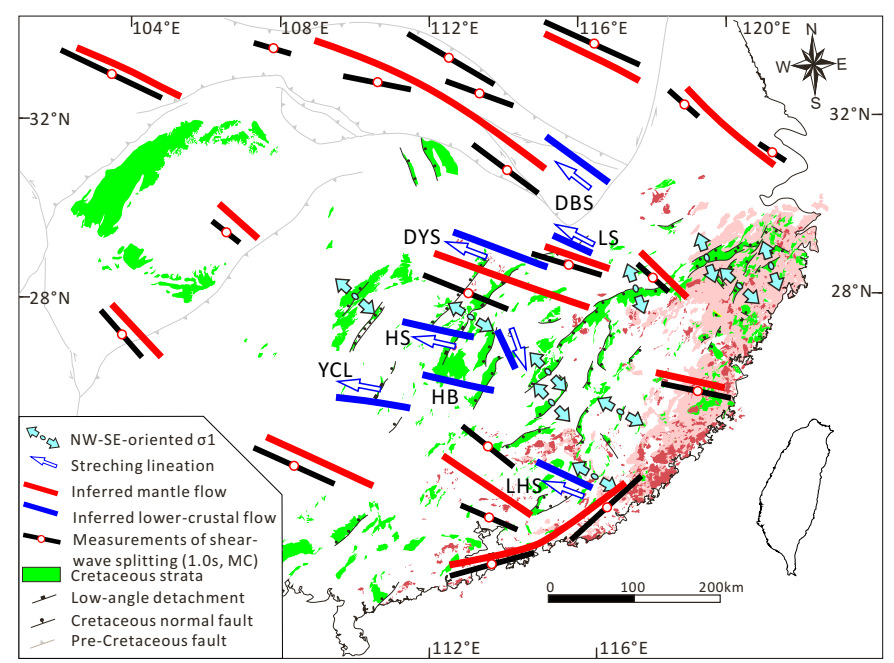

b

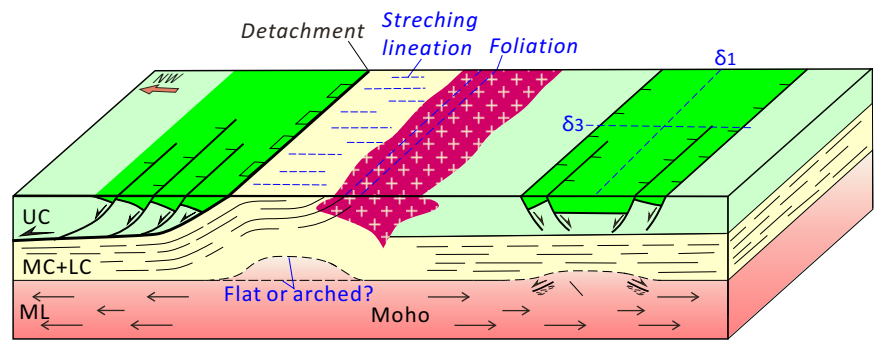

Fig. 4 Crustal and mantle flow patterns across the Cretaceous extensional system. a, Relationships between directions of stretching in metamorphic core complexes, and of seismic anisotropy in mantle lithosphere. Directions of the stretching lineation within metamorphic core complexes are determined from ref. 49. Abbreviations: DBS, Dabieshan; DYS, Dayunshan; HS, Hengshan; LS, Lushan; TBS, Tongbaishan; GS, Wugongshan; YCL, Yuechengling. The mantle seismic anisotropy is based on a compilation of shear-wave splitting measurements (MC method) from the XKS phases in ref. 41. Determinations of paleo-tectonic stress fields are from ref. 19. b, A cartoon showing the relation between surface stretching lineation and deep crustal flow. Abbreviations: UC, upper crust; MC, middle crust; LC, lower crust; ML, mantle lithosphere. 
a Depth-dependent extension in magma-poor conditions
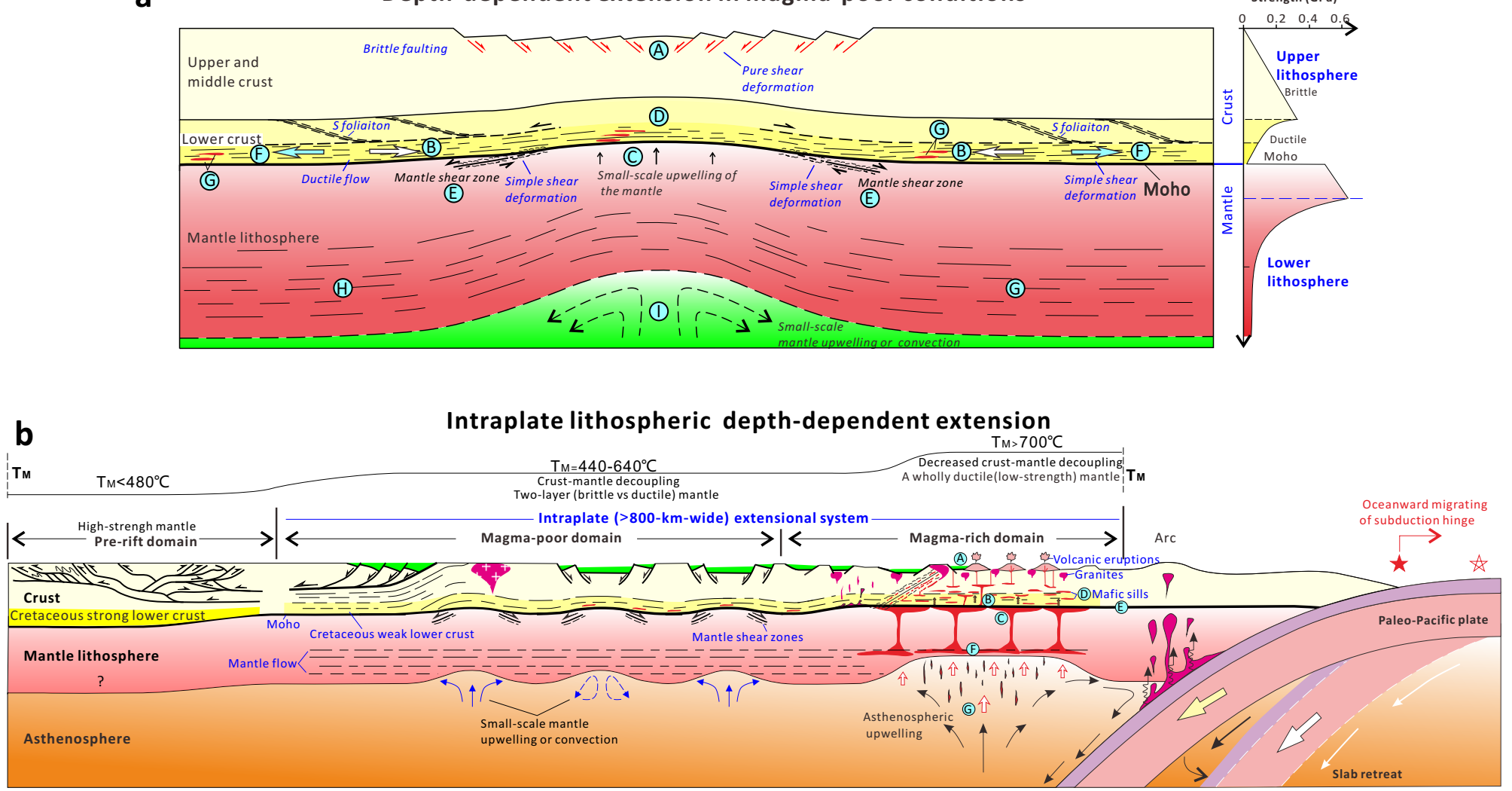

Fig. 5 Model of depth-dependent lithospheric extension for the intraplate extensional system. a, Four-layered, depth-dependent extension of the lithosphere in magma-poor conditions. The right side shows the schematic illustration of maximum rock strength as a function of depth for the continental lithosphere, from ref. 50. The depthdependent extension appears to evolve in a combined manner of pure- and simple- shear; the upper crust underwent stretching via pure shear, whereas simple shear dominated lateral flow in the lower crust and localized extension in the uppermost mantle. A-F illustrate two stages of the depth-dependent extension (see text for their typical characteristics). b, Configuration of lateral variation in modes of depth-dependent extension across the intraplate extensional system. Seismic data supporting this configuration: pre-rift domain, ref. 46; magma-poor domain, this study; magma-rich domain, ref. 43. 


\section{Supplementary Files}

This is a list of supplementary files associated with this preprint. Click to download.

- SUPPLEMENTARYINFORMATIONfinal.pdf 